\title{
Measuring cAMP Specific Phosphodiesterase Activity: A Two-step Radioassay
}

Connor M. Blair, \#, Jiayue Ling ${ }^{1, \#}$ and George S. Baillie ${ }^{1, \#, *}$

\author{
${ }^{1}$ Institute of Cardiovascular and Medical Sciences, School of Medical, Veterinary and Life Sciences, \\ University of Glasgow, Glasgow, UK \\ *For correspondence: George.baillie@glasgow.ac.uk \\ \#Contributed equally to this work
}

\begin{abstract}
[Abstract] Cyclic nucleotide degrading phosphodiesterase (PDE) enzymes are crucial to the fine tuning of CAMP signaling responses, playing a pivotal role in regulating the temporal and spatial characteristics of discrete cAMP nanodomains and hence the activity of cAMP-effector proteins. As a consequence of orchestrating CAMP homeostasis, dysfunctional PDE activity plays a central role in disease pathogenesis. This highlights the need for developing methods that can be used to further understand PDE function and assess the effectiveness of potentially novel PDE therapeutics. Here we describe such an approach, where PDE activity is indirectly measured through the direct quantification of radioactively tagged CAMP $\left(\mathrm{pmol} / \mathrm{min}^{-1} / \mathrm{mg}^{-1}\right)$. This method provides a highly sensitive tool for investigating PDE functionality.
\end{abstract}

Keywords: PDE, Phosphodiesterase, cAMP, Cyclic adenosine-monophosphate, 5'-AMP, 5' adenosine monophosphate

[Background] Cyclic 3',5'-adenosine monophosphate (cAMP) is a ubiquitously expressed second messenger, synthesised by adenylate cyclase enzymes (ACs), that acts as a master regulator of a broad spectrum of intracellular signalling pathways (Hayes and Brunton, 1982; Beavo and Brunton, 2002). Homeostatic regulation of CAMP is fine-tuned by phosphodiesterase enzymes (PDEs), rapidly degrading CAMP into 5'AMP (Baillie, 2009). PDEs consist of 11 families (PDE1-11) spanning over 100 isoenzymes (e.g., PDE4A1-PDE4A5), all with the ability to rapidly hydrolyse cyclic nucleotides (Conti and Beavo, 2007). Of these, PDE1-4, 7, 8, 10 and 11 possess the ability to catalyse the hydrolysis of cAMP. Compartmentalisation of specific PDE isoforms within discrete signalosomes is crucial to the spatiotemporal control of cAMP nanodomains, tightly regulating cAMP-effector protein activity (Blair and Baillie, 2019). In light of this, it is no surprise that aberrant PDE activity plays a central role in disease pathogenesis, with many PDEs being identified as a driving force in cardiovascular disease (Bobin et al., 2016), respiratory disease (Zuo et al., 2019), neurological disease (Knott et al., 2017) and cancers (Peng et al., 2018). Thus, research and development into novel and effective therapies targeting PDE activity remains a highly competitive area in drug discovery (Maurice et al., 2014; Baillie et al., 2019). This demonstrates a clear need for the development of assays with the ability to measure PDE activity, not only as a tool to investigate PDE activity/function in cellular signaling, but as a means of assessing and developing therapies targeting PDE activity.

Marchmont and Houslay (1980) previously described a method of measuring PDE activity, modified 
from a two-step procedure developed by Thompson and Appleman (1971). This radioassay directly quantifies the formation of radioactively tagged $8-\left[{ }^{3} \mathrm{H}\right]$ adenosine, formed as a result of cAMP hydrolysis by PDE within a given sample, allowing for the rate of CAMP hydrolysis to be determined. This highly sensitive assay has proven to be an invaluable tool in the understanding of unique PDE functionality and in assessing the effectiveness of novel PDE therapies (example studies utilising this method: Schafer et al., 2010; Moretto et al., 2015; Omar et al., 2019; Houslay et al., 2019). Here we present a straight-forward and effective procedure for indirectly measuring the activity of cAMP hydrolysing PDEs (Figure 1).

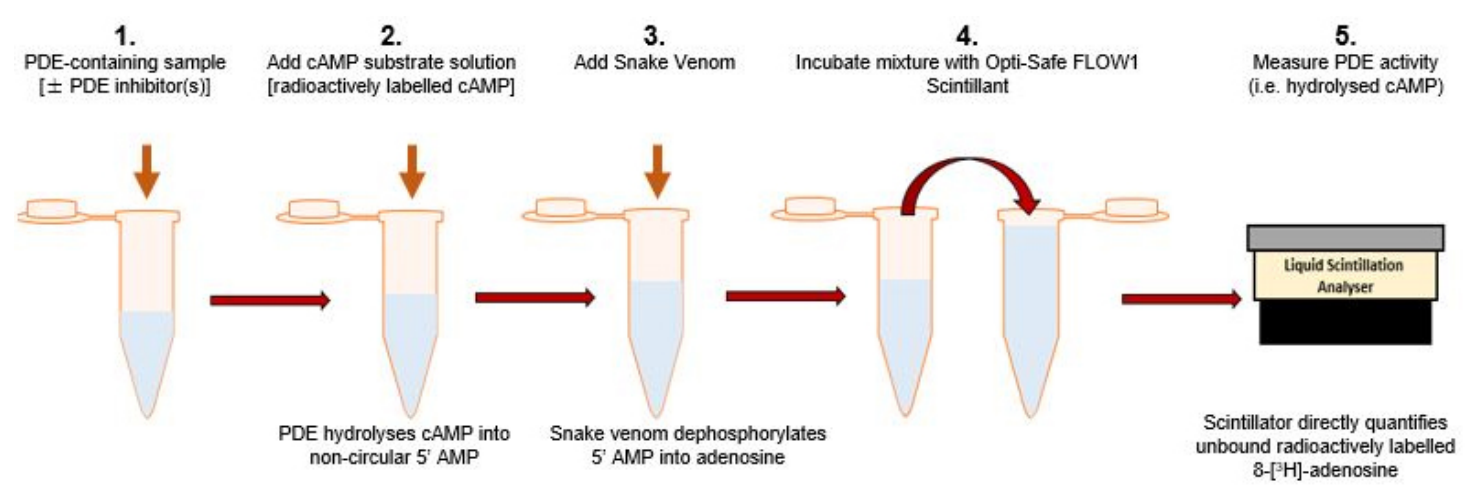

Figure 1. Simple schematic representing Phosphodiesterase Assay procedure

\section{Materials and Reagents}

1. Eppendorf ${ }^{\circledR}$ tubes (1.5 ml, clear tubes) (Greiner Bio-one, catalog number: $616-201$ )

2. Magnetic stir plate

3. $\mathrm{pH}$ paper

4. Tris Base (20 mM, pH 7.4 with $\mathrm{HCl})$ (Fisher Scientific, catalog number: 77-86-1)

5. $\mathrm{MgCl}_{2}$ (VWR, catalog number: 25108.260$)$

6. Dowex (Sigma-Aldrich, catalog number: 44340)

7. Absolute Ethanol (VWR, catalog number: 20821.330)

8. Deionized $\mathrm{H}_{2} \mathrm{O}$ (Milli-Q Pure)

9. Adenosine 3'5'-cyclic monophosphate, sodium salt (Sigma-Aldrich, catalog number: A6885, storage $-20^{\circ} \mathrm{C}$ )

10. $8-\left[{ }^{3} \mathrm{H}\right]$-cAMP substrate (Amersham Biosciences, catalog number: TRK304- $1 \mathrm{mCi}$, storage $-20^{\circ} \mathrm{C}$ )

11. Snake venom (Opiophagus Hannah) (Sigma, catalog number: V0376, storage $-20^{\circ} \mathrm{C}$ )

12. Opti-Flow SAFE 1 scintillant (Fisher Scientific (chemicals), catalog number: SC/9255/21, storage: room temperature)

13. $\mathrm{NaOH}$ (Fisher Scientific, catalog number: 4920/53)

14. $\mathrm{HCl}$ (Fisher Scientific, catalog number: H/1200/PB17)

15. Buffer A (see Recipes)

16. Buffer $B$ (see Recipes) 
17. Dowex Anion Exchange Resin (see Recipes)

18. Snake Venom (see Recipes)

19. cAMP Substrate Solution (see Recipes)

\section{Equipment}

1. TRI-CARB 2900TR Liquid Scintillation Analyzer (Packard) (Figure 2)

More up-to-date models exist (e.g., TRI-CARB 4910TR 110V Liquid Scintillation Counter, Packard)

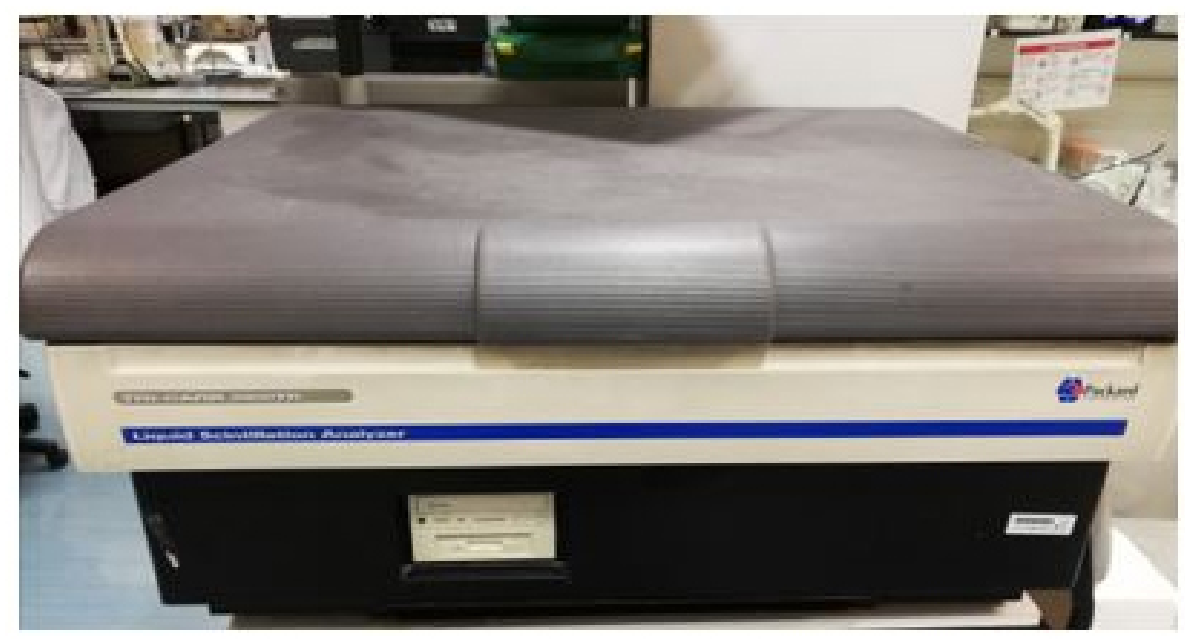

Figure 2. TRI-CARB 2900TR Liquid Scintillation Analyzer (Packard)

\section{Software}

1. Microsoft Excel

\section{Procedure}

1. Activating Dowex $1 \times 8-400$ Anion Exchange Resin.

Prepare large batches of Dowex resin:

a. Dissolve $400 \mathrm{~g}$ Dowex resin in $4 \mathrm{~L} 1 \mathrm{M} \mathrm{NaOH}$.

b. Mix solution at room temperature for $15 \mathrm{~min}$.

Note: To mix, a magnetic stir plate was used.

c. Allow resin to settle by gravity and remove supernatant.

d. Wash resin with $4 \mathrm{~L}$ of deionized $\mathrm{H}_{2} \mathrm{O}$ until $\mathrm{pH} 7.0$, using $\mathrm{pH}$ paper to measure.

Note: This may take up to $30 x$ washes.

e. At $\mathrm{pH} 7.0$, allow resin to settle and remove supernatant.

f. Suspend resin in $4 \mathrm{~L} 1 \mathrm{M} \mathrm{HCl}$ and mix for $15 \mathrm{~min}$ at room temperature.

g. Allow resin to settle and remove supernatant. 
h. Finally, wash resin in $4 \mathrm{~L}$ of deionized $\mathrm{H}_{2} \mathrm{O} 3 x$ until $\mathrm{pH} 3.0$, using $\mathrm{pH}$ paper to measure.

i. Stop mixing of solution after each wash to allow resin to settle before carefully removing deionized $\mathrm{H}_{2} \mathrm{O}$ and refilling with fresh deionized $\mathrm{H}_{2} \mathrm{O}$.

ii. Store resin in deionized $\mathrm{H}_{2} \mathrm{O}$ at $4{ }^{\circ} \mathrm{C}$.

iii. Add ethanol and deionized $\mathrm{H}_{2} \mathrm{O}$ to resin at a 1:1:1 ratio (dowex:ethanol: $\mathrm{dH}_{2} \mathrm{O}$ ) prior to use in assay.

2. Label triplicate $1.5 \mathrm{ml}$ Eppendorf ${ }^{\circledR}$ tubes per sample for assay (i.e., three technical replicates), including blanks. Incubate on ice.

3. Thaw all stock solutions being used.

4. Heat water-bath to $30^{\circ} \mathrm{C}$.

5. Prepare sample(s) to be assayed.

a. Incubate appropriate volume/concentration of PDE containing sample in $50 \mu \mathrm{l}$ Buffer A (Recipe 1).

Note: Pilot studies should be carried out to assess optimal concentration(s) of PDE containing sample being used. Typical concentration range of purified protein/PDE overexpressing cellular lysates: $1-10 \mu \mathrm{g} / \mu \mathrm{l}$ in a total volume of $50 \mu \mathrm{l} \mathrm{Buffer} \mathrm{A}$.

b. If investigating effect of inhibitor(s), make sample up in $40 \mu \mathrm{l}$ Buffer $A$ and $10 \mu \mathrm{l}$ of appropriately diluted inhibitor.

c. Add $50 \mu$ of Buffer A only for blanks.

6. Add $50 \mu \mathrm{l}$ of cAMP substrate solution (Recipe 5 ) to each PDE containing sample, including blanks, and vortex. Radioactively tagged cAMP in mix will be hydrolyzed to 5'-AMP in samples containing PDEs.

7. Incubate samples in a water bath at $30^{\circ} \mathrm{C}$ for $10 \mathrm{~min}$.

8. To terminate reaction (i.e., inactivate PDEs in sample), boil samples at $100{ }^{\circ} \mathrm{C}$ for $2 \mathrm{~min}$.

9. Cool samples on ice for $15 \mathrm{~min}$.

10. Add $1 \mathrm{mg} / \mathrm{ml}$ snake venom to each sample (i.e., $0.2 \mathrm{mg} / \mathrm{ml}$ final concentration), including blanks, and mix.

Note: Snake venom dephosphorylates the 5'-AMP to adenosine, preventing 5'-AMP from recircularising into $C A M P$.

11. Incubate samples in a water bath at $30^{\circ} \mathrm{C}$ for a further $10 \mathrm{~min}$.

12. Add $400 \mu$ l Dowex:ethanol: $\mathrm{dH}_{2} \mathrm{O}$ mix (aka Dowex anion exchange resin) to each sample and vortex. Ensure Dowex anion exchange resin is thoroughly suspended before adding to sample(s). Dowex anion exchange resin separates negatively charged cAMP from uncharged adenosine.

13. Cool samples on ice for a further $15 \mathrm{~min}$.

14. Vortex samples thoroughly and centrifuge at $10,000 \times g$ for 3 min at $4{ }^{\circ} \mathrm{C}$ in a refrigerated benchtop centrifuge.

15. Concurrently, add $1 \mathrm{ml}$ of Opti-Flow SAFE 1 scintillant to freshly labeled $1.5 \mathrm{ml}$ Eppendorf ${ }^{\circledast}$ tubes.

16. Remove $150 \mu$ l of clear supernatant from PDE containing reaction samples (see Step 14) and 
add to a appropriate scintillant tube containing $1 \mathrm{ml}$ of Opti-Flow SAFE 1 scintillation fluid.

17. Vortex all samples thoroughly.

18. Using a TRI-CARB 2900TR Liquid Scintillation Analyzer (Figure 2), measure/count unbound 8$\left[{ }^{3} \mathrm{H}\right]$-adenosine. This determines the rate of cAMP hydrolysis and thus PDE activity.

19. Analyse data (i.e., determine PDE activity. See Tables 1 and 2 for example set up/data analyses.)

Table 1. Example experimental set up

\begin{tabular}{|c|c|c|c|c|}
\hline \multicolumn{1}{|c|}{ Samples } & Buffer & Inhibitor & $\begin{array}{c}\text { cAMP Substrate } \\
\text { Solution }\end{array}$ & $\begin{array}{c}\text { Snake Venom } \\
\text { \& Dowex }\end{array}$ \\
\hline $\begin{array}{c}\text { Positive Control } \\
\text { PDE containing } \\
\text { sample }\end{array}$ & + & ++ & + \\
\hline$\quad \begin{array}{l}\text { PDE containing } \\
\text { sample + inhibitor }\end{array}$ & + & + & + & + \\
\hline $\begin{array}{c}\text { Negative [Blank] Control } \\
\text { - No PDEs in sample }\end{array}$ & + & & + & + \\
\hline
\end{tabular}

\section{Data analysis}

1. Analysing scintillation counter results (see Table 2)

(Example results: Omar et al., 2019)

a. Correct each sample to the background appropriately using blank reaction samples containing no PDEs.

b. Use background corrected counts to determine the initial rate of reaction (i.e., cAMP hydrolyzed/min).

c. To express results in cAMP hydrolyzed in $\mathrm{pM} / \mathrm{min}^{-1} / \mathrm{mg}^{-1}$ protein, pre-determine protein concentration of samples used in assay through a chosen standard method (e.g., Bradford assay, BCA assay, etc.).

d. Thus, use the following formula to determine the activity of a specific PDE within sample:

$$
\text { PDE activity }=2.61 \times \frac{\text { Average Value }- \text { Blank }}{\text { Average Total Count }} \times 10 \times \frac{1,000}{\mu \mathrm{g} \text { protein }}
$$

- $\mathrm{PDE}$ activity $=\mathrm{cAMP}$ hydrolyzed in $\mathrm{pM} / \mathrm{min}^{-1} / \mathrm{mg}^{-1}$

- 2.61 stands for the Dowex practical concentration

- 10 represents the concentration of cAMP (in pM) hydrolyzed in $100 \mu \mathrm{l}$ in $10 \mathrm{~min}$

e. To determine the effects of a selected PDE inhibitor, directly compare uninhibited control reactions to those that were inhibited and expressed as a percentage of the uninhibited control. 
Table 2. Example Data Set. PDE containing samples contained $5 \mu \mathrm{g}$ total purified PDE protein in $100 \mu \mathrm{l}$ sample.

\begin{tabular}{|c|c|c|c|c|c|c|}
\hline $\begin{array}{c}\text { Sample } \\
\text { Number } \\
\text { (Triplicates) }\end{array}$ & Sample ID & $\begin{array}{c}\text { 8- }\left[{ }^{3} \mathrm{H}\right]- \\
\text { adenosine } \\
\text { Count }\end{array}$ & $\begin{array}{c}\text { Average } \\
\text { Count }\end{array}$ & $\begin{array}{c}\text { PDE activity } \\
\text { (pM/ min-1/mg-1) }\end{array}$ & $\begin{array}{c}\text { PDE activity - } \\
\text { Mock } \\
\text { (Background } \\
\text { subtraction) }\end{array}$ & $\begin{array}{c}\text { \% Difference } \\
\text { vs. PDE } \\
\text { control }\end{array}$ \\
\hline & $\begin{array}{c}\text { Blank } \\
\text { Average Total } \\
\text { Count }\end{array}$ & & $\begin{array}{r}1000 \\
100000\end{array}$ & & & \\
\hline $\begin{array}{l}1 \\
2 \\
3\end{array}$ & Mock & $\begin{array}{l}1505 \\
1495 \\
1500\end{array}$ & 1500 & 26.1 & & \\
\hline $\begin{array}{l}1 \\
2 \\
3\end{array}$ & PDE & $\begin{array}{l}9500 \\
10000 \\
10500\end{array}$ & 10000 & 469.8 & 443.7 & 100 \\
\hline $\begin{array}{l}1 \\
2 \\
3\end{array}$ & $\begin{array}{l}\text { PDE + PDE } \\
\text { Inhibitor }\end{array}$ & $\begin{array}{l}2750 \\
3000 \\
3250\end{array}$ & 3000 & 104.4 & 78.3 & 17.65 \\
\hline
\end{tabular}

\section{$\underline{\text { Notes }}$}

1. ${ }^{3} \mathrm{H}_{1}$ (Tritium)

Half Life: 12.3 Years

Specific activity: $3.59 \mathrm{E}+14 \mathrm{~Bq} \cdot \mathrm{g}^{-1}$

\section{$\underline{\text { Recipes }}$}

1. Buffer $A$

$20 \mathrm{mM}$ Tris- $\mathrm{HCl}(\mathrm{pH} 7.4)$

Store at $4{ }^{\circ} \mathrm{C}$

2. Buffer B

$20 \mathrm{mM}$ Tris- $\mathrm{HCl}(\mathrm{pH} 7.4)$

$10 \mathrm{mM} \mathrm{MgCl}_{2}$

Store at $4{ }^{\circ} \mathrm{C}$

3. Dowex anion exchange resin

Dowex:ethanol:deionized $\mathrm{H}_{2} \mathrm{O}$ [1:1:1 ratio]

Store at $4{ }^{\circ} \mathrm{C}$

4. Snake venom $(10 \mathrm{mg} / \mathrm{ml}$ stock; derived from Ophiophagus Hannah)

Dilute to $1 \mathrm{mg} / \mathrm{ml}$ in Buffer $A$ 
Store at $-20^{\circ} \mathrm{C}$

5. cAMP substrate solution

$2 \mu \mathrm{l}$ 'cold' cAMP (i.e., unlabeled) [1 mM cAMP]

$3 \mu \mathrm{l}$ 'hot' cAMP (i.e., 8-[33]-labeled) [1 $\mu \mathrm{Ci} / \mu \mathrm{l}]$

$995 \mu \mathrm{l}$ Buffer B

Store at $-20^{\circ} \mathrm{C}$

\section{Acknowledgments}

Connor Blair is funded by an Industrial PhD studentship that is supported by Portage Glasgow Ltd and the College of Medical, Veterinary and Life Sciences, University of Glasgow.

\section{Competing interests}

The authors have no competing interests.

\section{References}

1. Baillie, G. S. (2009). Compartmentalized signalling: spatial regulation of cAMP by the action of compartmentalized phosphodiesterases. FEBS J 276(7): 1790-1799.

2. Baillie, G. S., Tejeda, G. S. and Kelly, M. P. (2019). Therapeutic targeting of 3',5'-cyclic nucleotide phosphodiesterases: inhibition and beyond. Nat Rev Drug Discov 18(10): 770-796.

3. Beavo, J. A. and Brunton, L. L. (2002). Cyclic nucleotide research -- still expanding after half a century. Nat Rev Mol Cell Biol 3(9): 710-718.

4. Blair, C. M. and Baillie, G. S. (2019). Reshaping cAMP nanodomains through targeted disruption of compartmentalised phosphodiesterase signalosomes. Biochem Soc Trans 47(5): 1405-1414.

5. Bobin, P., Belacel-Ouari, M., Bedioune, I., Zhang, L., Leroy, J., Fischmeister, R. and Vandecasteele, G. (2016). Cyclic nucleotide phosphodiesterases in hear and vessels: A therapeutic perspective. Arch Cardiovasc Dis 109(6-7): 431-443.

6. Conti, M. and Beavo, J. (2007). Biochemistry and physiology of cyclic nucleotide phosphodiesterases: essential components in cyclic nucleotide signaling. Annu Rev Biochem 76: 481-511.

7. Hayes, J. S. and Brunton, L. L. (1982). Functional compartments in cyclic nucleotide action. $J$ Cyclic Nucleotide Res 8(1): 1-16.

8. Houslay, K. F., Fertig, B. A., Christian, F., Tibbo, A. J., Ling, J., Findlay, J. E., Houslay, M. D. and Baillie, G. S. (2019). Phosphorylation of PDE4A5 by MAPKAPK2 attenuates fibrin degradation via p75 signalling. $J$ Biochem 166(1): 97-106.

9. Knott, E. P., Assi, M., Rao, S. N. R., Ghosh, M. and Pearse, D. D. (2017). Phosphodiesterase Inhibitors as a Therapeutic Approach to Neuroprotection and Repair. Int J Mol Sci 18(4): E696 
10. Marchmont, R. J. and Houslay, M. D. (1980). A peripheral and an intrinsic enzyme constitute the cyclic AMP phosphodiesterase activity of rat liver plasma membranes. Biochem J 187(2): 381-392.

11. Maurice, D. H., Ke, H., Ahmad, F., Wang, Y., Chung, J. and Manganiello, V. C. (2014). Advances in targeting cyclic nucleotide phosphodiesterases. Nat Rev Drug Discov 13(4): 290 314.

12. Moretto, N., Caruso, P., Bosco, R., Marchini, G., Pastore, F., Armani, E., Amari, G., Rizzi, A., Ghidini, E., De Fanti, R., Capaldi, C., Carzaniga, L., Hirsch, E., Buccellati, C., Sala, A., Carnini, C., Patacchini, R., Delcanale, M., Civelli, M., Villetti, G. and Facchinetti, F. (2015). CHF6001 I: a novel highly potent and selective phosphodiesterase 4 inhibitor with robust anti-inflammatory activity and suitable for topical pulmonary administration. J Pharmacol Exp Ther 352(3): 559567.

13. Omar, F., Findlay, J. E., Carfray, G., Allcock, R. W., Jiang, Z., Moore, C., Muir, A. L., Lannoy, M., Fertig, B. A., Mai, D., Day, J. P., Bolger, G., Baillie, G. S., Schwiebert, E., Klussmann, E., Pyne, N. J., Ong, A. C. M., Bowers, K., Adam, J. M., Adams, D. R., Houslay, M. D. and Henderson, D. J. P. (2019). Small-molecule allosteric activators of PDE4 long form cyclic AMP phosphodiesterases. Proc Natl Acad Sci U S A 116(27): 13320-13329.

14. Peng, T., Gong, J., Jin, Y., Zhou, Y., Tong, R., Wei, X., Bai, L. and Shi, J. (2018). Inhibitors of phosphodiesterase as cancer therapeutics. Eur J Med Chem 150: 742-756.

15. Schafer, P. H., Parton, A., Gandhi, A. K., Capone, L., Adams, M., Wu, L., Bartlett, J. B., Loveland, M. A., Gilhar, A., Cheung, Y. F., Baillie, G. S., Houslay, M. D., Man, H. W., Muller, G. W. and Stirling, D. I. (2010). Apremilast, a cAMP phosphodiesterase-4 inhibitor, demonstrates antiinflammatory activity in vitro and in a model of psoriasis. Br J Pharmacol 159(4): 842-855.

16. Thompson, W. J. and Appleman, M. M. (1971). Multiple cyclic nucleotide phosphodiesterase activities from rat brain. Biochemistry 10(2): 311-316.

17. Zuo, H., Cattani-Cavalieri, I., Musheshe, N., Nikolaev, V. O. and Schmidt, M. (2019). Phosphodiesterases as therapeutic targets for respiratory diseases. Pharmacol Ther 197: 225242. 